\title{
Espaços de lazer para a terceira idade: sua análise por meio de diferentes vertentes
}

\author{
Leisure facilities for the elderly: their analysis through different strands
}

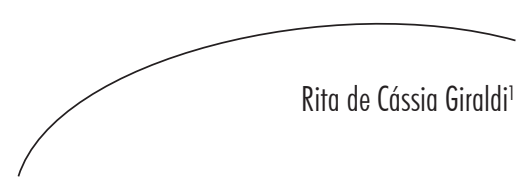

\section{Resumo}

Este artigo objetivou, por meio de revisão bibliográfica, elaborar uma discussão teórica sobre os dois universos aqui propostos - espaços de lazer e terceira idade -, refletindo acerca das variáveis projetuais dos espaços de lazer para esta parcela da população. O propósito foi apontar que, aos espaços de lazer pensados somente nas funções a que se prestam, devem ser agregados novos elementos, visando otimizar seus usos e interações. Também se buscou refletir sobre como a questão projetual do espaço cria uma "realidade tridimensional" no plano das ideias, cujo resultado é a materialização do projeto na obra. Portanto, é preciso refletir sobre a atribuição dos significados simbólicos de um espaço, especificamente o de lazer, pois eles passam a integrar a ambiência e esta, por sua vez, atua sobre o imaginário de seus usuários, possibilitando ou não a intensificação de seus usos, principalmente no que diz respeito à prática dos lazeres. No que diz respeito à população eleita para a pesquisa, verificou-se que estudos em diversas áreas do saber estão estabelecendo um panorama mais condizente sobre o que é considerada terceira idade no século XXI.

\section{Abstract}

This article aimed, through literature review, develop a theoretical discussion about the two universes proposed here - leisure facilities and seniors - reflecting about the projective variables of leisure facilities for this population. The purpose was to point out that the spaces of leisure considered only in the functions they provide, must be added new elements to optimize their uses and interactions. We also sought to reflect on how the projective issue of space creates a "three dimensional reality" in terms of ideas, the result of which is the realization of the project's work. Therefore, we must reflect on the allocation of symbolic meanings of space, specifically leisure, as they become part of the ambience and this, in turn, acts on the imagination of its users, or not allowing the intensification of its uses, especially with regard to the practice of leisure. With regard to the population selected for the research, it was found that studies in several areas of knowledge are establishing a more consistent picture of what is considered old age in the twenty-first century.

Curso de Lazer e Turismo, Escola de Artes, Ciências e Humanidades. Universidade de São Paulo. São Paulo, SP, Brasil.

Palavras-chave: Espaços de Lazer. Terceira idade. Idosos. Ambiência.

Key words: Leisure facilities. Elderly. Ambience. 


\section{INTRODUÇÃO}

Partindo da análise de diversos autores acerca do significado da denominada "terceira idade" e de como o lazer se apresenta nesta fase de vida, buscou-se compreender como se apresentam os espaços de lazer pensados para atender às demandas necessárias a este público. Para tanto, foi adotada uma visão pluridimensional de análise dos espaços de lazer, de modo a explorálos por meio de suas "verdadeiras" funções ou de sua configuração formal, de seus efetivos usos enquanto espaços planejados para as atividades direcionadas e dos significados atribuídos a esses por seus usuários.

Apesar de grandes contribuições para a compreensão desta faixa populacional, seja no que se refere a sua inserção social, seja nas atividades oferecidas para esse público em específico, o presente artigo estabeleceu um novo enfoque aos espaços de lazer voltados a essa população que, na maioria das vezes, ocupa espaços de lazer pensados e planejados para uma população ativa economicamente.

Este artigo tem como objetivo elaborar uma discussão teórica acerca dos dois universos aqui propostos: espaços de lazer e terceira idade, refletindo acerca das variáveis projetuais dos espaços de lazer para esta parcela da população.

\section{O IDOSO E 0 LAZER}

Odebate acerca do envelhecimento tem gerado estudos em diferentes áreas do saber, onde as buscas por traçar um panorama frente à realidade de um país que está se tornando envelhecido têm gerado divergências de opinião entre os autores ao categorizarem essa população. Inegavelmente, os estudos sobre a saúde destes indivíduos, seja na área da Medicina e Nutrição, seja na área da Educação - principalmente da Educação Física -, assim como na área da Assistência Social e do Direito, apontam resultados positivos para uma melhor compreensão acerca do que seja esta categoria vivencial denominada "idoso".
A questão do envelhecimento sempre foi um assunto bastante polêmico, dada a dificuldade em se delimitar uma baliza a partir da qual uma pessoa passa a se encontrar nesta fase de vida. É de senso comum que já começamos a envelhecer desde nosso nascimento. Devemos refletir sobre os aspectos fisiológicos, sociais, psicológicos e legais, dentre outros. O que se percebe é que, em muitos casos, as abordagens desses aspectos são tratadas de forma apartada, embora devamos ressaltar que todos se apresentam imbricados no cotidiano de quem atingiu a denominada "terceira idade", também mencionada como a "melhor idade" ou de outras formas, sendo o indivíduo que atingiu essa faixa etária considerado "idoso".

Cada uma dessas denominações pode ser compreendida sob determinada ótica de estudo, ou seja, a denominação "idoso" estaria relacionada às questões biológicas, a "terceira idade" à esfera econômica produtiva e "a melhor idade" à área do lazer. O que se verifica, também, é um embate acerca da abrangência da faixa etária denominada "idoso", uma vez que ora se pensa em adotar como parâmetro os fatores biológicos, ora os sociais, ora os culturais ou ainda, os comportamentais. No entanto, neste milênio, todos os estudos referentes à terceira idade se deparam com novos paradigmas sobre o assunto, tendo em vista que a expectativa de vida humana tem ultrapassado os limites outrora conhecidos.

No que diz respeito aos aspectos fisiológicos, os limites se caracterizam pelo fato de que nosso organismo possui um ciclo de vida e, devido aos progressos da medicina, nossa expectativa de vida tem aumentado significativamente nos últimos vinte anos. ${ }^{1,2}$ Em 2012, ano-base 2011, a expectativa de vida do brasileiro atingiu 74 anos e 29 dias, de acordo com o IBGE, ${ }^{1}$ ultrapassando os limites anteriormente estabelecidos. As projeções previstas para o ano de 2014 por este Instituto ${ }^{2}$ são que a população na faixa etária de 65 a 79 anos será composta por 5.452 .784 indivíduos.

Como afirma Albuquerque, ${ }^{3} \quad$ "[...] é convencional identificar o início da velhice com a idade de 65 anos, para as nações desenvolvidas 
(ONU), e tomar tal idade como limiar que identifica o idoso, convenção esta que, via de regra, está estreitamente associada às políticas de seguridade social, em particular às de aposentadoria."

Afinal, tais parâmetros são necessários para estabelecer legalmente aqueles que possuem seus direitos adquiridos, de modo a possibilitarem a garantia material de sobrevivência neste período da vida.

Quanto ao aspecto psicológico, a terceira idade pode ser analisada sob diferentes óticas, desde sua autoimagem até as fragilidades afetivas e emocionais que se intensificam com a idade. Neste sentido, os estudos da Psicossociologia muito contribuíram para tal. Baltes \& Baltes ${ }^{4}$ afirmam que: "[...] o envelhecimento bemsucedido precisa de uma avaliação sustentada em uma perspectiva multidimensional, na qual fatores objetivos e subjetivos sejam considerados dentro de um contexto cultural, que contém demandas específicas."

Outro aspecto dos estudos da terceira idade tem como enfoque a questão legal expressa pela Lei $\mathrm{n}^{\mathrm{o}} 10.741$, de $1^{\circ}$ de outubro de $2003,{ }^{5}$ também conhecida como Estatuto do Idoso, cujo teor estabelece uma proteção a estes sujeitos em diferentes situações cotidianas. Também segundo essa lei, o lazer é considerado como um direito assegurado pela família, pela comunidade, pela sociedade e pelo poder público.

Por fim, o aspecto social é o mais significativo para o presente artigo, tendo em vista que o lazer, enquanto comportamento, é uma atividade aceita socialmente na atualidade. No âmbito do social, a terceira idade é compreendida como a fase pós-trabalho e teoricamente aquela que poderia ser vivenciada plenamente em seus lazeres. A denominada "fase pós-produção" surge por resquícios de uma vida centrada num sistema produtivo, segundo a qual no início do século passado os homens trabalhavam em sistemas fabris e tinham sua atividade laboral regida pelo ritmo das máquinas. Ser produtivo, dentro deste contexto, era a máxima que regia a vida humana. Não mais estar apto a desenvolver tais tarefas, por não mais ser produtiva, relegava uma camada populacional a um segundo plano, externando a concepção dominante vigente desde as sociedades pré-industriais, quando a ideia era de que a vida humana era dividida em duas fases: preparação para o trabalho e produção, o que transformava as pessoas em produtores e consumidores. Atualmente, uma nova pedagogia que visa a uma educação permanente e contínua define o indivíduo pertencente à terceira idade como: "[...] aquele que vê no amanhã a continuidade do trabalho do hoje, aquele que não fica à espera do descanso eterno, que vai à luta, que busca preencher os espaços da vida, que se vê como elemento útil à sociedade. Enfim, aquele que acredita e demonstra que tem experiências a serem relatadas e que, acima de tudo, é ainda capaz de grandes realizações. ${ }^{6}$

Uma vez que o limite da longevidade tem mudado paulatinamente devido aos avanços da medicina e dos serviços sociais e, também, devido à melhoria das condições de vida, fazendo com que os jovens se tornem adultos cada vez mais cedo e a velhice fisiológica chegue cada vez mais tarde, a mobilidade e a saúde têm importantes efeitos, tanto na quantidade, quanto na qualidade do lazer das pessoas da terceira idade.

Nesta situação, o grande volume de tempo livre - advindo da aposentadoria - pode trazer novas oportunidades de ocupação, satisfazendo uma variedade de interesses que na fase produtiva de suas vidas eram relegados a planos inferiores. $\mathrm{Na}$ realidade, as pessoas aposentadas enfrentam o problema de o que fazer com todo o tempo livre de que dispõem. Dentro desta concepção, a terceira idade da vida seria caracterizada como a grande fase do lazer, da realização pessoal, do investimento em si próprio no sentido da autorrealização, da criatividade e da participação.

No entanto, ainda falta preparo para se ingressar nessa fase da vida, além de preconceitos em relação ao lazer. Como consequência, a aposentadoria é sentida como um grande tempo vazio, de inutilidade, de ócio e de isolamento. 
Mas, não é esta a atual realidade para parte da população de idosos que atualmente pode se engajar em diferentes projetos oferecidos especialmente para este público. ${ }^{7}$ Tais projetos envolvem aspectos relacionados à sociabilidade, à melhoria da saúde física e mental, bem como da qualidade de vida e, neste último, podemos encontrar a prática do lazer.

O lazer hoje é uma realidade na vida humana, característico das sociedades pós-industriais. Pode ser compreendido como a prática de atividades escolhidas de acordo com as apetências de cada um, sendo realizado no denominado tempo livre, ou seja, um período de tempo no qual não temos nenhum comprometimento social e podemos nos dedicar àquilo que realmente desejemos fazer. Isso significa alterar o sentido da vida de ter mais para ser mais, onde a questão central recai sobre "como viver ou simplesmente sobreviver". ${ }^{8}$ Mas o lazer também deve ser pensado sob a ótica das políticas públicas, de modo a atender às diferentes faixas populacionais, principalmente no que diz respeito aos equipamentos oferecidos." "De modo geral, os idosos têm mais tempo para o lazer, a cujo cultivo são estimulados [...], seguindo os pressupostos da teoria da atividade. Contudo, não é a atividade em si que leva à satisfação, mas a percepção subjetiva do reconhecimento e da integração social a partir das atividades realizadas [...]."

Hoje, alguns segmentos de serviços de lazer estão adequados para atender à demanda emergente desse público, tais como: universidade aberta à terceira idade, clube da terceira idade, academias com atividades específicas para este segmento, assim como pacotes e equipamentos turísticos e outros. No entanto, para que a prática das atividades de lazer seja possível e plena, seus espaços e equipamentos devem ser pensados de modo diferenciado, não se pautando somente nos aspectos funcionais da atividade.

ESPAÇOS DE LAZER PARA A TERCEIRA IDADE: UMA VISÃO PLURIDIMENSIONAL

No que se refere ao estudo dos espaços de lazer em geral, as abordagens ainda seguem os princípios da arquitetura moderna, onde a forma segue a função, ou seja, os espaços são pensados sob a ótica da ergonomia e das atividades a serem nele praticadas, possibilitando uma percepção direta de quais atividades podem ser praticadas em quais locais. Tais propostas podem limitar a criatividade de seus usuários, limitando as práticas e, em alguns casos, destinando o espaço ao esvaziamento.

Em se tratando da terceira idade, a oferta de espaços de lazer deve ser repensada devido às particularidades desta população, não só no que diz respeito a algumas limitações físicas particulares desta faixa etária, mas principalmente devido ao repertório e à importância da memória para estes. Deste modo, torna-se necessário repensar as questões projetuais dos espaços de lazer, e para tanto podemos decompô-los numa visão tríplice, cujo enfoque compreende três categorias: os aspectos formais, os sociais e os do imaginário.

É importante esclarecer que, embora centralizemos nossa análise no que se refere aos espaços de lazer, isso não significa que tal visão não possa ser aplicada às diversas tipologias espaciais - espaços domésticos, de trabalho, de circulação e urbanos.

A primeira das categorias de análise dos espaços de lazer diz respeito aos seus aspectos formais. Ao enfocar essa perspectiva de análise, estamos trabalhando com a forma final que um espaço toma em sua materialização.

Ao tratar de resultados formais dos espaços de lazer, deparamo-nos com dois momentos de concepção dentro da arquitetura moderna. Em princípio, a configuração dos espaços segue critérios objetivos, que podem ser arrolados hierarquicamente de acordo com a função primeira - associada a outras - a que se destina à construção. A posição das funções depende da importância atribuída a cada uma delas, embora todas estejam relacionadas entre si, fazendo parte do cotidiano de maneira complexa e quase inseparável. O predomínio de umas sobre as outras atua de modo marcante, diferenciando-as significativamente. 
Na medida em que obedecem a certas normas e regras, os espaços acabam por ser resultado direto da adoção de um programa de necessidades. Esse programa, abstraído da realidade cotidiana, reflete o produto final da transformação das necessidades em aspirações e destas, em exigências. Tais quesitos só se manifestam concretamente na obra arquitetônica se houver disponibilidade de recursos técnicos ou de meios para sua realização. Esse programa das necessidades é considerado, segundo Graeff," como o "primeiro passo concreto de realização da obra de arquitetura".

A caracterização física do espaço arquitetônico tem como base os aspectos mecânicos da função - sendo esta entendida como a atividade humana exercida no ambiente edificado, onde sua ordenação é calcada nos aspectos físicos e ergonômicos de cada atividade. $\mathrm{O}$ conceito de função assume significado disciplinar completo a partir do momento em que institui entre as partes constitutivas da obra arquitetônica uma relação determinada. Assim, por meio da observação da "conduta sistemática" - conduta planejada, controlada -, torna-se possível decidir o programa que norteará o projeto.

Tal postura é reflexo do Positivismo aplicado à arquitetura. Como os homens geralmente têm consciência de suas diversas formas de atuação e da sequência em que elas são executadas, tornase factível uma prospecção dos diversos usos do espaço. O estudo das funções tende a constituir um complexo de conhecimentos dirigidos à transformação da realidade material observáveis, segundo determinados procedimentos de intervenção projetual baseados em dados essencialmente empíricos.

Voltando à problemática dos espaços de lazer, é de se notar que alguns pressupostos básicos orientam sua configuração espacial, visto que cada área em particular possui um "programa de necessidades" e a associação de todos os programas deve se processar de forma harmônica, para que o empreendimento tenha boas possibilidades de êxito funcional e econômico.

As áreas de lazer dentro desta concepção são espaços que vêm se ampliando ultimamente, refletindo uma tendência ascendente da prática esportiva, do lazer e dos cuidados com a saúde. Suas instalações requerem projetos especiais, com um custo de implantação elevado. Seus itens são projetados e dimensionados de acordo com normas técnicas que procuram equacionar as dimensões ideais e o fluxograma dos espaços.

Gostaríamos de enfatizar que os usos específicos de cada espaço prendem-se, por um lado, às normas sociais, que contam com todo um sistema de sanções e proibições para assegurar ao espaço uma função fundamental; e por outro, às apetências motivacionais individuais.

Devemos, ainda, considerar que: “[...] Os rituais da vida cotidiana e as condições da vida social deixam profundas marcas nos edifícios, através das mudanças que introduzem no conteúdo dos programas de necessidades. É nesse fato, principalmente, que se apoia a ideia de arquitetura como espelho da vida social. A arquitetura reflete realmente aspectos da vida social, mas isso não faz dela mero espelho da sociedade. Porque ela não se limita a amoldarse às exigências da vida. Assim como pode refletir aspectos da vida e das transformações sociais, a arquitetura pode atuar como fator de transformações [..]."12

Partindo da imbricação do social com o espaço arquitetônico, podemos abordar a segunda variável da visão tríplice do espaço, ou seja, seus aspectos sociais. A interação entre os fatores sociais de uma determinada comunidade - neste caso, a terceira idade -, e seu espaço físico tem sido frequentemente objeto de análises das Ciências Sociais, com prioridade para a abordagem das questões urbanas. A cidade é, assim, adotada como palco da concretização das relações humanas em seus diversos níveis: analisam-se os aspectos físicos das ruas, as fachadas dos edifícios, os monumentos (como reflexo dos aspectos culturais da comunidade) e também as diversas interações relacionais que ocorrem nesses locais. No entanto, tais estudos praticamente se limitam à esfera teórica, já que, apesar da importância de se conhecerem os efeitos do meio ambiente construído sobre o comportamento e a saúde dos homens, as observações resultantes estão longe 
de uma interpretação consensual, principalmente porque ainda não existe, a seu respeito, uma postura teórica geral. ${ }^{13}$

Entre as linhas teóricas adotadas para a análise espacial, podemos destacar a determinista e a da possibilidade. Segundo a primeira, as mudanças no aspecto formal dos espaços promovem alterações no comportamento dos indivíduos, podendo gerar ou inibir desde o bemestar até uma possível interação social. Tratase de uma postura discutível, já que adota uma análise unidirecional. No que tange à segunda, a da possibilidade, a mesma considera que o espaço físico contém limitações; apenas promove possibilidades a partir das quais as pessoas elegem comportamentos baseados principalmente em critérios culturais. O fato de os seres humanos atuarem de diferentes modos, em diversos lugares e épocas, permite-nos inferir que essas diferenças comportamentais resultam do ajustamento dos indivíduos às normas de comportamento próprias de cada cultura em particular. Este ajuste ocorre mais facilmente na medida em que o meio físico oferece índices para o comportamento, o que pode ser considerado como uma forma de comunicação não verbal, realizada por símbolos que comunicam os valores socioculturais. Em síntese, o homem só utiliza um espaço quando este é passível de uma decodificação.

Os poucos estudos existentes acerca dos espaços internos e seus usuários têm sido trabalhados por alguns segmentos da Sociologia, Antropologia e Psicossociologia. Assim, ao se analisarem os espaços particulares, extrapolam-se dos estudos dos comportamentos individuais, ${ }^{13,14}$ para o exame dos fenômenos sociais. Para o último caso, o espaço passa a ser considerado como um sistema socioemocional que serve de suporte à expressão das atitudes sociais. Tais estudos chamam a atenção para o fato de o comportamento espacial humano ter valor psicológico, representado por uma linguagem que se expressa na realidade social. $\mathrm{Na}$ área da Psicossociologia, Fischer ${ }^{15}$ faz uma análise teórica dos aspectos emocionais provocados pelos arranjos espaciais, levando em consideração os diversos significados que lhes podem ser atribuídos. Para ele, "O homem e o ambiente não podem ser mais considerados como entidades fechadas, estranhas uma à outra; entre elas se estabelece uma relação que não é nem puramente de integração, nem forçosamente antagonista, mas que é estruturada por uma influência recíproca. É precisamente o estudo dessa interdependência onde os arranjos espaciais são considerados como um dos modos de organização da vida social que faz o objeto de uma psicossociologia do espaço. Os processos estudados nos esclarecem sobre sua dimensão significativa: para compreender as situações, deve-se apreender, de uma parte, a importância da estruturação do espaço, e por outra parte, a maneira pela qual ele é vivido pelas pessoas. Assim, o espaço não pode ser reduzido a servir somente de cenário ou de molde aos fenômenos humanos. Ao contrário, é uma teoria aberta do homem que é proposta por essa nova abordagem."15

$\mathrm{Na}$ área específica da Ecologia Humana, Sommer ${ }^{16}$ realizou diversas pesquisas com o intuito de analisar a interação dos espaços internos e o comportamento de seus usuários. Todavia, seu trabalho não é o pioneiro na área, pois em 1931 o sociólogo Bogardus (citado por Sommer) ${ }^{16}$ afirmou que "apenas na medida em que os fatos sociais e físicos podem ser reduzidos a fatos espaciais, ou com estes correlacionados, é que podem ser medidos".

Em suas observações, Sommer ${ }^{16}$ detectou, por exemplo, que a mera disposição de assentos numa sala de espera pode favorecer ou não a sociabilidade entre seus usuários. $\mathrm{O}$ design de uma simples cadeira pode interferir no tempo de ocupação de um espaço, na medida em que ele contribua para aumentar ou diminuir a sensação de bem-estar; e assim por diante. O intuito de tais estudos era propor técnicas que ajudassem a esclarecer e compreender as reações das pessoas em determinados ambientes.

Ainda com relação aos aspectos sociais do espaço - mas desta vez especificamente na área do lazer - Dumazedier ${ }^{17}$ abordou a relação espaço/ lazer/social, onde o espaço de lazer, além de ser 
um espaço cultural, é também social, na medida em que nele "se entabulam relações específicas entre seres, grupos, meios, classes"; e, mais que isso, ele é "determinado pelas características da população que o utiliza, pelo modo de vida dos diferentes meios sociais que o frequentam". ${ }^{17}$

Dentro da perspectiva de Chombart de Lauwe $^{18}$ acerca dos componentes objetivos e subjetivos do espaço social e aplicando-a aos espaços de lazer, estes podem ser vistos sob dois enfoques: o cenário espacial de cada um deles, com suas fronteiras físicas, disposição de mobiliário e rede de comunicações com outros espaços constituem os componentes objetivos; já os componentes subjetivos seriam a forma como os usuários percebem, identificam e caracterizam esses mesmos espaços. Indiscutivelmente, tal ideia/imagem reflete valores, tradições culturais e aspirações de seus sujeitos os quais, em nossa pesquisa, apresentam uma rica diversidade, já que seus usuários muitas vezes pertencem a núcleos culturais diferentes.

Assim, o espaço é portador de um valor resultante do significado que se pode extrair das hierarquizações, hábitos e linguagens criadas por seus usuários; e são os diferentes comportamentos sociais que nos traduzem esse significado. Podemos acrescentar que, com base nos pontos expostos acima, temos a possibilidade de apreender o porquê de diferentes intensidades no uso dos ambientes. Essa afirmação está respaldada na síntese da noção de estilo de vida proposta por Rapoport, ${ }^{19}$ segundo a qual os elementos cultura, postura ante o mundo, valores, imagem/esquema, estilo de vida e atividades estão todas relacionadas sequencialmente.

Como o sentido da relação espaço/indivíduo baseia-se na percepção e interpretação do primeiro pelo segundo, as relações mudam em função dos diferentes tempos em que os indivíduos vivem - tempo de trabalho e tempo de lazer. Assim, concordamos com Bachelard ${ }^{20}$ quando afirma que "[...] o espaço convida à ação, e antes da ação a imaginação trabalha. Ela ceifa e lavra. Seria preciso falar dos benefícios prestados por todas essas ações imaginárias."
Seja no âmbito do profissional, seja no do usuário, a apreensão do mundo real e sua passagem para a condição de mundo percebido sofrem necessariamente influências do imaginário. E aqui podemos iniciar o último aspecto de nossa análise, ou seja, o espaço do imaginário.

Dentro da esfera dos lugares, acreditamos que nos espaços de lazer podemos encontrar muitos dos elementos inerentes aos seres humanos: os sentidos, a percepção, a memória, as emoções, os desejos e, principalmente, o imaginário. Este último permeia os demais e fornece, a cada um de nós, o real significado dos ambientes em que vivemos.

Mas em que consiste realmente o imaginário? Podemos entendê-lo como sendo a forma pela qual o mundo é percebido e transformado em representações, as quais passam a reger a dinâmica emocional e a estrutura da percepção e do conhecimento do mundo pelo homem. Esta representação do mundo não resulta do conhecimento puro, mas das percepções e elaborações originárias das experiências, que por sua vez são produzidas pela relação dialética entre o homem e sua circunstância.

Podemos afirmar ainda que este imaginário se traduz na apreensão mental do mundo real; seu sentido baseia-se, principalmente, nas relações entre as imagens que são obtidas do concreto, mas encarnam valores, expectativas, crenças e esquemas imaginativos. Estes esquemas incorporam certos tipos de ideais e um determinado conhecimento de como o mundo funciona.

Para o imaginário, o espaço se define como o jogo das presenças e ausências, que podem se alternar. Nele, a simulação dos objetos resgata para o usuário suas imagens primitivas. Essa concepção de imagem é baseada na teoria de Boulding, citado por Rapoport. ${ }^{19}$ Segundo ele, qualquer conduta humana depende da imagem apreendida, sendo esta entendida como todo o conhecimento subjetivo acerca do mundo e sobre nós mesmos. Boulding ${ }^{19}$ classifica a imagem em dez categorias: espacial, temporal, 
relacional, pessoal, de valorização, afetiva, de certeza e incerteza, de realidade e irrealidade, de público e privado - sendo que nem todas estão respaldadas no espacial. Nosso espaço imaginário também possui a imagem como ponto de partida. Para melhor compreendê-lo, tomamos emprestados alguns elementos dos estudos da poética e, mais especificamente, dentro do raciocínio de Bachelard.*20,21

Assim, durante o transcorrer de nossas vidas, nutrimos nossas mentes, por meio dos sentidos, com infinitas imagens; destas, algumas são carregadas de significado e outras nem tanto. Tais imagens são extraídas do cotidiano em que vivemos e têm como cenário os espaços vividos; mas elas não se isolam em sua significação e, ao contrário, tendem precisamente a ultrapassá-la. É assim que, conforme o ambiente, poderemos sentir familiaridade, espontaneidade e até mesmo a depressão.

As diversas sensações que podem nos ocorrer em diferentes espaços são fruto de dois elementos em particular: a ambiência e o imaginário. Embora eles não atuem separadamente na origem da sensação, pertencem, no entanto, a esferas do conhecimento distintas - ou seja, a ambiência pertence à esfera do espaço e o imaginário à esfera da mente.

Qualquer ambiente é essencialmente nominado, já que foi concebido com vistas a um exato preenchimento - seguindo os princípios funcionalistas - de acordo com a relação que pode ser estabelecida, em termos de conexão espacial, com a distribuição do mobiliário e física, com a estrutura do espaço considerado como um todo.

Cada conjunto de objetos contidos em determinado espaço possui relações objetivas com as funções a que se destinam; mas sua descrição, feita por meio da linguagem, geralmente não é própria das formas descritas, mas das analógicas e até das opositivas - o que

\footnotetext{
* GASTON BACHELARD possui diversos estudos na área da poética, onde relaciona imagem e imaginário com as esferas da Natureza e do ser.
}

de certa forma as distancia da realidade narrada. Assim, nenhuma descrição, por mais exata que seja, é capaz de resgatar o conjunto dos elementos que compõem um espaço, ou suas relações de posição e dimensões. Isso acontece principalmente porque, ao narrarmos um ambiente, recorremos às imagens que ficaram gravadas em nossa memória e revelam um espaço que não éna realidade, já que o imaginário também se faz presente na descrição.

Alguns desses não ser revelam-se de imediato por oposição, antes mesmo de serem objetos de nossa observação, pois os espaços adquirem sentido mediante as ações que neles possam ser executadas pelo $e u$. O espaço pode, portanto, acolher ou modificar nossos hábitos enquanto tais, e sua habitabilidade refletirá o grau de disponibilidade que ele apresenta em face de nossos desejos conscientes ou ainda latentes.

Ao descrevermos um espaço arquitetônico, será impossível percebermos seu sentido "puro", visto que o relacionaremos com uma série de parâmetros que, no conjunto, retratam a história de nossos desejos pessoais, a estrutura referencial de nossas percepções e nossas relações com os grupos sociais. De algum modo, cada descrição é uma visão-juízo, um fazerer referência a e um fluir em direção a.

Complementando o sentido de ambiência, Coutinho ${ }^{22}$ escreve que “[...] O indivíduo é um valor arquitetônico assim que penetra o íntimo espaço, adquirindo, no momento da porta, essa qualidade de interferir na atmosfera em plenitude, quebrando a inteireza em vigor; ao mesmo tempo em que estabelece outra disposição no vazio e, ao retirar-se, caso seja ele o único visitador da hora, restitui ao espaço a anterior feição [...]."

Assim, ao nos retirarmos do ambiente, levamos conosco as imagens gravadas através da retina em nosso inconsciente e é neste último que encontramos o universo do imaginário. Ele é o elemento fundamental da imaginação, que no psiquismo humano corresponde a vivenciar a novidade, o inusitado, por meio da imaginação. As imagens fornecidas pela percepção são associadas 
e "distorcidas", mas não estão sujeitas a uma confrontação com a realidade, porque o homem em si é passado, presente e se projeta no futuro.

As imagens são, portanto, mutáveis e, ao penetrar no mundo do imaginário, fazem-nos sonhar; abstraídas por nossas mentes; e dissociadas de sua forma primeira, abrem os horizontes da mais profunda irrealidade do psiquismo.

O imaginário, como elemento integrante da vida cotidiana, tem papel de extrema importância: não só pelo elemento "fascínio" com que envolve os fatos cotidianos, mas principalmente como forma de manifestação do eu face à realidade. As imagens se associam e se movimentam num trajeto contínuo do real ao imaginário. Elas devem ser tomadas como uma totalidade e estudadas no seu conjunto, mesmo que aparentemente fragmentadas, pois representam valores pessoais de sinceridade e nos fornecem subsídios para uma reelaboração do real.

Das diversas realidades que se nos apresenta, o espaço construído é uma das que mais nos convida à viagem imaginária, pois a ambiência desses espaços possui elementos que evocam "sonhos", devido aos diferentes significados que eles podem adotar. Assim: "[...] A imaginação, em nós fala (projeta), nossos pensamentos falam (projetam). Toda atividade humana deseja falar (projetar). Quando essa palavra (essa imagem) toma consciência em si, então a atividade humana deseja escrever (edificar), isto é, agenciar os sonhos e os pensamentos." ${ }^{21}$

Pelo exposto, os espaços de lazer podem ser considerados como os que mais se predispõem às manifestações do imaginário por meio da ambiência.

\section{O REPENSAR DOS ESPAÇOS DE LAZER PARA A TERCEIRA IDADE}

A ambiência se traduz na percepção dos espaços e na interação deste com seus usuários. Deste modo, o lazer acontece em determinadas ambiências (compostas pelos aspectos físicos, sociais e do imaginário) que requerem elementos específicos para surpreender seus usuários, pois as pessoas procuram em seu tempo livre sair do cotidiano e romper com as barreiras sociais. Entretanto, elas também procuram um mínimo de segurança e conforto, por isso a ambiência de espaços de lazer exige elementos antagônicos que se integrem entre si.

Além disso, tais espaços também precisam estar contextualizados, formando a ambiência que deve estar inserida no lugar, na paisagem, na cultura local, e devem possuir valores simbólicos e significativos para as pessoas que deles usufruem, com maior atenção se estas forem pertencentes à terceira idade. Desse modo, ao pensarmos na relação ambiência e terceira idade devemos ter em mente que o equipamento a ser implantado deve atender aos diferentes aspectos acima mencionados para que possamos ter um optimu de uso.

Esta breve abordagem sobre a ideia de que os espaços de lazer podem extrapolar a mera visão formal de suas configurações nos fez ver que os aspectos sociais e do imaginário são elementos de extrema importância para os usuários e que os mesmos não são levados em consideração quando da elaboração dos projetos. Pudemos ainda notar que, dependo de como a obra arquitetônica é formalmente organizada, pode acarretar diferentes intensidades de uso do espaço. Isto nos demonstrou que, seja atualmente ou num futuro próximo, os princípios adotados para os programas das necessidades e os partidos arquitetônicos - principalmente na área dos espaços de lazer voltados à terceira idade - devam ser repensados, adotando uma nova visão para a organização e estruturação de seus espaços.

A Arquitetura, enquanto representação imaginária, possibilita a materialização de sonhos, seja dos profissionais que a conceberam, seja de quem dela se utiliza. E as ausências e presenças sentidas em seus espaços produzem o simulacro da vida. Este simulacro age como duplicação das experiências reais, atribuindo ao espaço real uma segunda realidade, que se manifesta principalmente pela abertura a experiências subjetivas, vividas por meio de nossa própria realidade ou de nossa consciência e que acabam superando a experiência individual do real concreto. 


\section{CONCLUSÃO}

Concluímos que para que um espaço adote um significado a seus usuários, necessariamente ele deve transformar-se de quantitativo em qualitativo.

Frente ao exposto, os equipamentos destinados à terceira idade devem atender não só aos aspectos físicos visando a um uso adequado dentro dos princípios da ergonomia, mas também aos

\section{REFERÊNCIAS}

1. Instituto Brasileiro de Geografia e Estatística. Sala de Imprensa. [acesso em 19 Mar 2012]. Disponível em: http://www1.ibge.gov.br/home/presidencia/noticias/ noticia_visualiza.php?id_noticia $=266 \&$ idpagina $=1$.

2. Instituto Brasileiro de Geografia e Estatística. Projeção da população do Brasil por sexo e idade . 2013 [acesso em 15 Mai 2014]. Disponível em: http:// www.ibge.gov.br/home/estatistica/populacao/ projecao_da_populacao/2013/default.shtm.

3. Albuquerque SML. Envelhecimento ativo: desafio do século. São Paulo: Andreoli; 2008.

4. Baltes PB, Baltes MM. Successful aging: perspectives from the behavioral sciences. Cambridge: Cambridge Press; 1990.

5. BRASIL. Lei $n^{\circ} 10.741,01$ de outubro de 2003. Dispõe sobre o Estatuto do Idoso e outras providências. Diário Oficial da União, 3 Out 2003. Seção 1.

6. Giubilei S. Uma pedagogia para o idoso. Terc Idade 1993;5(7):10-4

7. Barros MML. Trajetória dos estudos de velhice no Brasil. Sociologia [Internet] 2006 [acesso em 29 Mai 2014];52:109-32. Disponível em: http:// www.scielo.oces.mctes.pt/scielo.php?pid=S087365292006000300006\&script=sci_abstract

8. Dumazedier J. A revolução cultural do Tempo Livre. Camargo LOL, tradutor. São Paulo: Studio Nobel; 1994.

9. Marcelino NC. Políticas Públicas setoriais de lazer: o papel das prefeituras. Campinas, SP: Autores Associados; 1996.

10. Doll J. Educação, cultura e lazer: perspectivas de velhice bem sucedida. In: Neri AL, organizadora. aspectos que possibilitam o social e o imaginário, sobretudo devido ao fato de que, como coloca Bosi, ${ }^{23}$ nesta fase de nossa vida "[...] se existe uma memória voltada para a ação, feita de hábitos, e outra que simplesmente revive o passado, parece ser esta a dos velhos já libertos das atividades profissionais e familiares. Se tais atividades nos pressionam, nos fecham o acesso para a evocação, inibindo as imagens de outro tempo, a recordação nos parecerá algo semelhante ao sonho, ao devaneio tanto contrasta com nossa vida ativa."

Idosos no Brasil: vivências, desafios e expectativas na terceira idade. São Paulo: Abramo; 2007. p. 109-23

11. Graeff EA. Edifício. $3^{a}$ ed. São Paulo: Projeto; 1986. p. 3. (Cadernos Brasileiros de arquitetura, vol. 7).

12. Graeff EA. Edifício. $3^{\mathrm{a}}$ ed. São Paulo: Projeto; 1986. p. 38. (Cadernos Brasileiros de arquitetura, vol. 7).

13. Hall ET. A dimensão oculta. Rio de Janeiro: Francisco Alves; 1977.

14. Storr A. A agressão humana. Rio de Janeiro: Zahar; 1970.

15. Fischer GN. La psychosociologie de l'espace. Pina LW, tradutor. Paris: Press Universitaires de France; 1981.

16. Sommer R. Espaço pessoal: as bases comportamentais de projetos e planejamentos. São Paulo: EPU/EDUSP; 1973.

17. Dumazedier J. Sociologia empírica do lazer. São Paulo: Perspectiva; 1979.

18. Chombart de Lauwe, PH. Hombres y ciudades. Barcelona: Labor; 1976.

19. Rapoport A. Aspectos humanos de la forma urbana: hacia una confrontación de las Ciencias Sociales con el diseño de la forma urbana. Barcelona: Gustavo Gilli; 1978.

20. Bachelard G. A poética do espaço. São Paulo: Martins Fontes; 1989.

21. Bachelard G. O ar e os sonhos: ensaios sobre a imaginação do movimento. São Paulo: Martins Fontes; 1990.

22. Coutinho E. O espaço da arquitetura. São Paulo: Perspectiva; 1977.

23. Bosi E. Memória e sociedade: lembranças de velhos. São Paulo: Companhia das Letras; 1994. 